\title{
Medical Image of the Week: Spontaneous Pneumothorax in End Stage Fibrotic Lung Disease
}

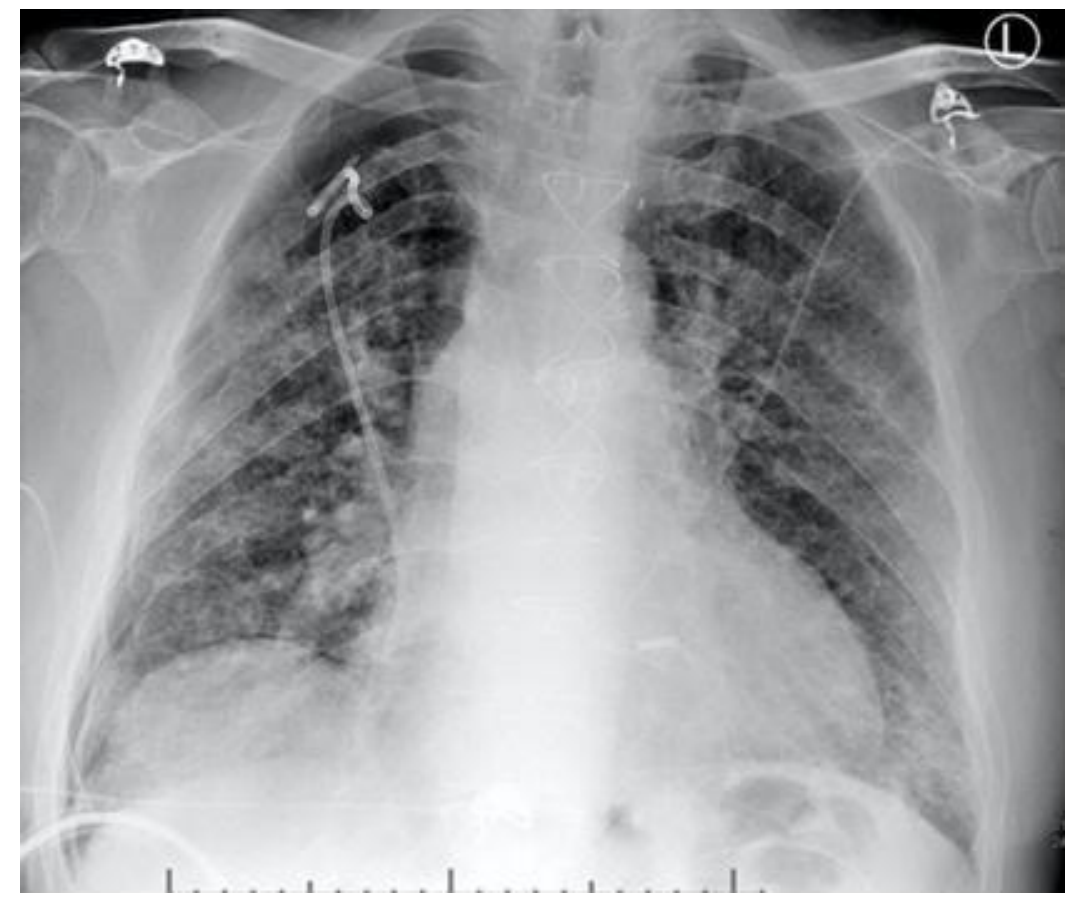

Figure 1. Chest $x$-ray showing moderate-sized right pneumothorax with a pigtail chest tube in place, diffuse reticular interstitial opacities.

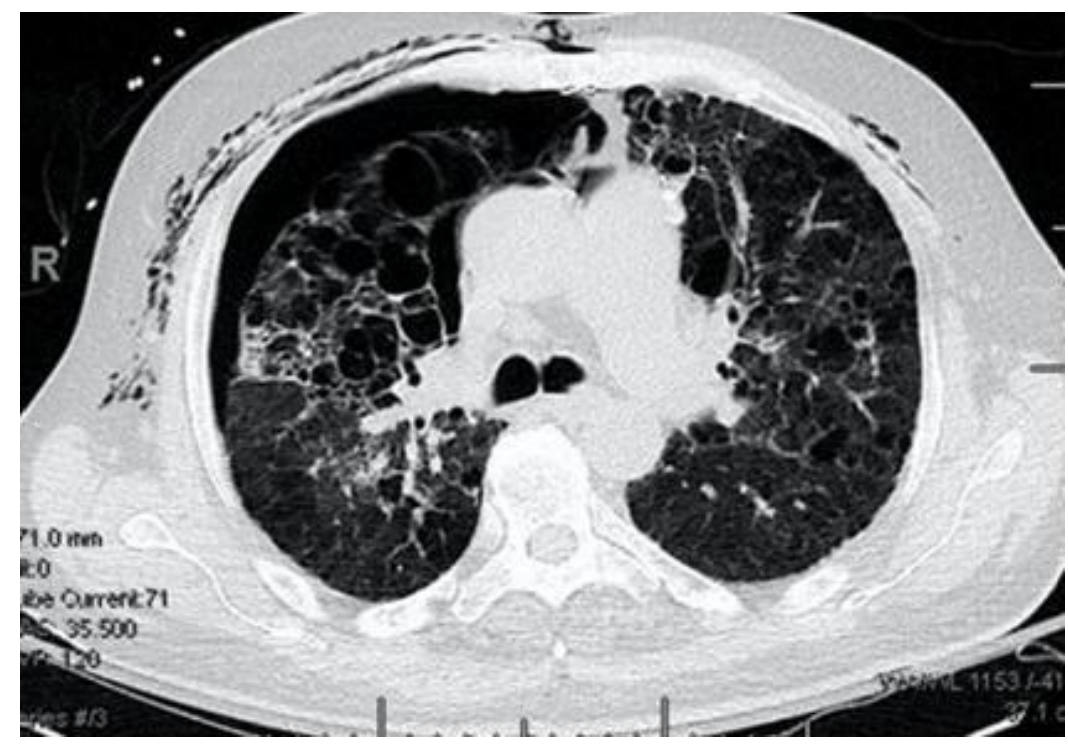

Figure 2. Chest CT showing extensive centrilobular emphysema, moderate right pneumothorax with pigtail chest drain on the right, subpleural reticular opacities with peripheral and basilar preponderance suggesting interstitial fibrotic lung disease, and diffuse lung cysts - heterogenous in size. 
A 61-year-old nonsmoking man with chronic obstructive lung disease, pulmonary hypertension, pulmonary fibrosis, hypertension, coronary artery disease with congestive heart failure, presented with recurrent pneumothorax, pneumomediastinum, extensive subcutaneous emphysema and bronchopleural fistula.

The patient reported ongoing symptoms of exertional dyspnea, fatigue, and coughing for years. His environmental exposures were notable for exposure to birds since early childhood. He had 6 cockatiels and 2 doves living inside his home and is directly responsible for their care. Former occupational exposures include painting and sandblasting. Family history was notable for early onset non specified lung disease in his father, and rheumatoid arthritis in his mother.

Lung function testing performed prior to the bronchopleural fistula revealed moderate obstructive ventilatory defect with severely limited DLCO. Chest x-ray (Figure 1) revealed a moderate-sized right pneumothorax with a pigtail chest tube in place and diffuse reticular interstitial opacities. His CT chest (figure 2) revealed extensive subcutaneous emphysema, diffuse lung cysts that are heterogenous in size, and subpleural reticular opacities with peripheral and basilar preponderance. Bronchoalveolar lavage revealed no infection, with predominant monocyte/ macrophages. Alpha-1 antitrypsin (A1AT) was normal, as were autoimmune panels. A hypersensitivity pneumonitis panel revealed positive lgG to Aureobasidium pullulans. A presumptive diagnosis of chronic hypersensitivity pneumonitis was made.

Spontaneous pneumothorax (SP), a potentially life-threatening complication, is defined by the accumulation of air in the pleural space with secondary lung collapse, and can be categorized as primary (without apparent lung disease) or secondary pneumothorax. While chronic obstructive pulmonary disease and Pneumocystitis jirovecii pneumonia are the most common causes of secondary spontaneous pneumothorax, other structural lung diseases such as fibrotic lung diseases have also been linked to SP. Interstitial lung diseases distort lung architecture and trigger formation of subpleural blebs that are susceptible to rupture leading to extra-alveolar air collection and air leakage in the pleural space. Presence of persistent air leak, as in our case, mandates surgical consideration to accelerate recovery and prevent recurrence of secondary SP.

Roula Altisheh MD and Tara Carr MD

Division of Pulmonary, Allergy, Critical Care and Sleep Medicine Banner-University Medical Center

Tucson, AZ USA

\section{References}

1. Sahn S, Heffiner J. Spontaneous Pneumothorax. N Engl J Med 2000; 342:868-74 [CrossRef] [PubMed]

2. Onuki T, Ueda S, Yamaoka M, Sek iya Y, Yamada H, Kawakami N, Araki Y, Wakai $\mathrm{Y}$, Saito K, Inagaki M, Matsumiya N. Primary and secondary spontaneous 
pneumothorax: prevalence, clinical features, and in-hospital mortality. Can Respir J. 2017: 6014967. [CrossRef] [PubMed]

3. Koschel D, Handzhiev S, Cardoso C, Rolle A, Holotiuk O, Höffken G.

Pneumomediastinum as a primary manifestation of chronic hypersensitivity pneumonitis. Med Sci Monit. 2011 Dec;17(12):CS152-5. [PubMed]

4. Ichinose J, Nagayama K, Hino H, et al. Results of surgical treatment for secondary spontaneous pneumothorax according to underlying diseases. Eur J Cardiothorac Surg. 2016;49(4):1132-6. [CrossRef] [PubMed] 